\title{
Ground loading from BLEVE through small scale experiments: Experiments and results
}

\author{
R. Eyssette ${ }^{\mathrm{a}, \mathrm{b}}$, F. Heymes ${ }^{\mathrm{a}, *}$, A.M. Birk ${ }^{\mathrm{b}}$ \\ a LSR Laboratory for Risk Science, IMT Mines Ales, France \\ ${ }^{\mathrm{b}}$ Department of Mechanical and Materials Engineering, Queen's University, Kingston, Ontario, Canada
}

\section{A B S T R A C T}

The ground force generated by a BLEVE is a hazard that has been seldom studied, even though BLEVE has been source of many research works in the past decades. However, emergency responders have been asking questions the risk and consequences of a BLEVE on a bridge and other critical infrastructures for a while, with no answer so far. Moreover, a tank truck accident in Bologna in August 2018 has shown that bridge collapse may result from such scenario.

This paper presents the experimental work done with a small scale apparatus reproducing realistic BLEVE failure with a cylindrical tube. Load cells were placed under the base plate holding the tube to measure the local ground force generated by the explosion. Forces from $10 \mathrm{kN}$ to $55 \mathrm{kN}$ were measured for a $50 \mathrm{~mm}$ diameter tube with $300 \mathrm{~mm}$ length failing at pressures from 10 to 32 Bar. The ground force signals are interpreted together with the imaging and internal pressure signal. The synchronization between violent boiling, repressurization in the vessel and strong ground force is clear through this comparison. Different ground force signals were observed depending on the fill level and weakened length of the tube. The maximum ground force and impulse vary almost linearly with failure pressure and liquid fill level. It is less clear for the influence of weakened/ opening length of the tube. More data is required to conclude on this parameter influence.

Keywords:

Boiling Liquid Expanding Vapor Explosion

Explosion

High speed imaging

Explosive phase change

Failure analysis

\section{Introduction}

BLEVE (Boiling Liquid Expanding Vapor Explosion) incidents have happened around the world for more than 60 years now, on industrial sites as well as on the roads and rails during transportation of pressure liquefied gases in pressure vessels. This type of incident is feared because of the dramatic consequences it often induces. The deadliest case of BLEVE, which happened in Mexico in 1984, took over 650 lives, led to over 6000 injuries, without mentioning the tremendous material cost of the incident (Pietersen, 1988). Even though not all BLEVEs are as deadly, they are dangerous and feared by the industries using pressure liquefied gas storage vessels. The material consequences are also often costly. It is thus of major importance to understand the hazards of such an event, to prevent its dramatic consequences and react better when facing an upcoming BLEVE.
A BLEVE is a physical explosion due to vapour release and violent boiling of the superheated liquid. The hazards from a BLEVE include:

- Overpressure from a lead shock wave. This shock wave is argued in recent work to be generated by the vapour space in the vessel (Eyssette, 2018).

- Vessel fragment propulsion from the expansion energy of the whole fluid in the vessel. These fragments are far reaching with trajectories difficult to predict.

- Potential fireball or vapour cloud explosion if the content of the vessel is flammable

- Toxic cloud dispersion if the content is toxic

- Blast wind and dynamic pressure from the two-phase flow following the boiling process. This is arguably taking its source in the liquid boiling and expansion.

- The local ground loading due to the content release

Many prediction models have been established on several of these hazards. A good review work on the history of BLEVE and the prediction of its various hazards has been done a decade ago

\footnotetext{
* Corresponding author.

E-mail address: frederic.heymes@mines-ales.fr (F. Heymes).
} 


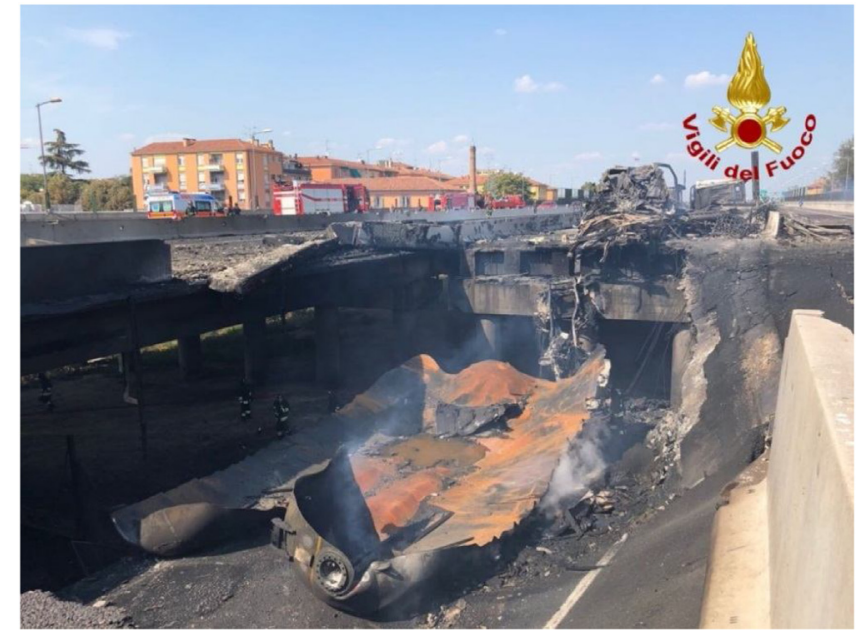

Fig. 1. Opened vessel and collapsed bridge after a tanker truck accident leading to a BLEVE on an elevated highway near Bologna, August 2018. Picture from the website of Italian firefighters (Vigilfuoco.tv, 2018).

(Abbasi and Abbasi, 2007). The ground force hazard is however not studied so far in the case of BLEVE.

Understanding the physics of BLEVE phenomenon is the starting point of most of these models. A common assumption in many of these models is the use of the liquid energy to estimate the overpressure of a shock. A few references argue that it is a wrong approach to modeling the overpressure, as it seems to be driven only by the vapour phase expansion (Baker et al., 1983; Birk et al., 2018). However the liquid should still be considered to the hazardous behavior of BLEVE. Indeed most of the thermal energy is stored in the liquid phase, due to its larger enthalpy compared to vapour phase. Thus the boiling process is largely responsible in the fragment propelling hazard, as well as the dynamic loading of surrounding structures and ground loading.

As mentioned above, very little work exists on the prediction of the force generated on the ground when a vessel is subjected to a BLEVE, even though various situations require its investigation. If the vessel is held above ground by a structure on an industrial site, chances are that the structure will not resist the explosion, and structures and objects under the vessel will be destroyed, or structures around the vessel may be pulled down. Emergency responders have also been asking for some years about the consequences of a BLEVE from a tanker truck accident on a bridge: could it destroy a bridge if such incident happened?

A recent incident gave an answer to this question for one specific case. In August 2018, a BLEVE incident happened in Italy: a road tanker truck was involved in a road accident on a highway bridge in the surroundings of Bologna Italy. Two trucks following each other collided. One of them was loaded with liquid propane, the other one was carrying various flammable chemical products. Various flammable liquids were spilled. A fire started in the chemical products transport trailer. Once the fire developed, after a certain time, a very large explosion occurred. It was a blatant case of BLEVE. The vessel was found flattened, and part of the bridge under the truck collapsed after the explosion (Fig. 1). This incident confirmed that the matter needs to be addressed.

Bridges subject to explosions have been studied in literature, with simulations for different bridge configurations (Foglar et al., 2017; Hashemi et al., 2016; Winget et al., 2005), feedback from real accidental cases (Wang et al., 2014) and experiments on smaller scale concrete blocks (Wang et al., 2013). For most of these studies, the load on the bridge from the explosion is found through the TNT-equivalent model to estimate the overpressure generated in

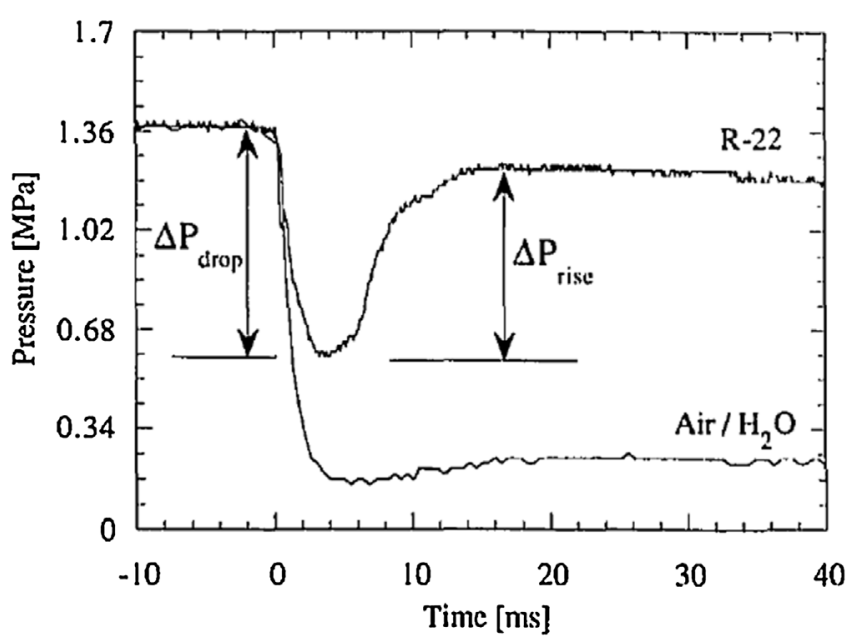

Fig. 2. Characteristic pressure history for venting of R-22 and pressurized water (Barbone, 1994).

the explosion. The ground force hazard is however not studied so far in the case of BLEVE.

Rapid boiling during a BLEVE may produce a significant thrust effect, but little data can be found on the resulting force. Pipe ruptures of superheated liquids were studied by (Baum and Parry, 1992) and showed the damage involved with the thrust from superheat boiling. These models assume a steady state propagation of the crack along the pipe. Other configurations were studied by the same author, either vertical cylindrical vessel failing at its top, propelling the end cap (Baum, 1995), or failing at the bottom (Baum, 1998). Further investigation of the BLEVE physics in the horizontal cylinder configuration is required to understand its impact on the ground.

Since rapid boiling during a BLEVE is expected to contribute to a dynamic pressure load, several studies investigated transients of pressure while vessels and cylinders open with pressure liquefied gas containment, emphasizing the pressurization process happening due to the superheat boiling inside the container (Barbone, 1994). Fig. 2 shows the difference of pressure between a superheated liquid venting (refrigerant R-22) and venting with no superheat (compressed air and water) in a rectangular vessel of $260 \mathrm{~mL}$ bursting on its top ( $2 \mathrm{~cm}$ wide $\mathrm{x} 19 \mathrm{~cm}$ high $\mathrm{x} 7.5 \mathrm{~cm}$ deep). Pressure is measured near the opening of the vessel. The pressure drop (quantified by $\Delta P_{\text {drop }}$ ) is the result of the fluid expansion. In the case of superheated $\mathrm{R}-22$, the boiling process is visible through a pressure rise $\left(\Delta P_{\text {rise }}\right)$ preventing the pressure to drop down to atmospheric conditions. This pressure rise shows the intensity of the boiling process. It must be noted that the pressure remains almost constant for some time after the pressure rise in the vessel and then it decays down to ambient pressure. This is due to the restricted cross section area of the vessel, choking the two-phase flow and spanning the full venting of the vessel over a time longer than the $40 \mathrm{~ms}$ visible on the plot.

These results show that during a BLEVE, boiling may be sufficiently fast to keep pressure in the vessel during release, sustaining the release for a longer time that without liquid boiling. This explains why BLEVE should be expected to exert a significant force and impulse on a bridge. However no measurements of this hazards were made on cylindrical vessel bursting into a BLEVE. This lack of measurements and quantification of the hazard leads to a lack of modeling and prediction for hazard assessment and prevention.

This paper aims to fill the first gap mentioned above. It presents the results of ground loading measurements on a small scale BLEVE experimental apparatus, and identify some correlation behaviors between the entry parameters of the experiment and the ground 


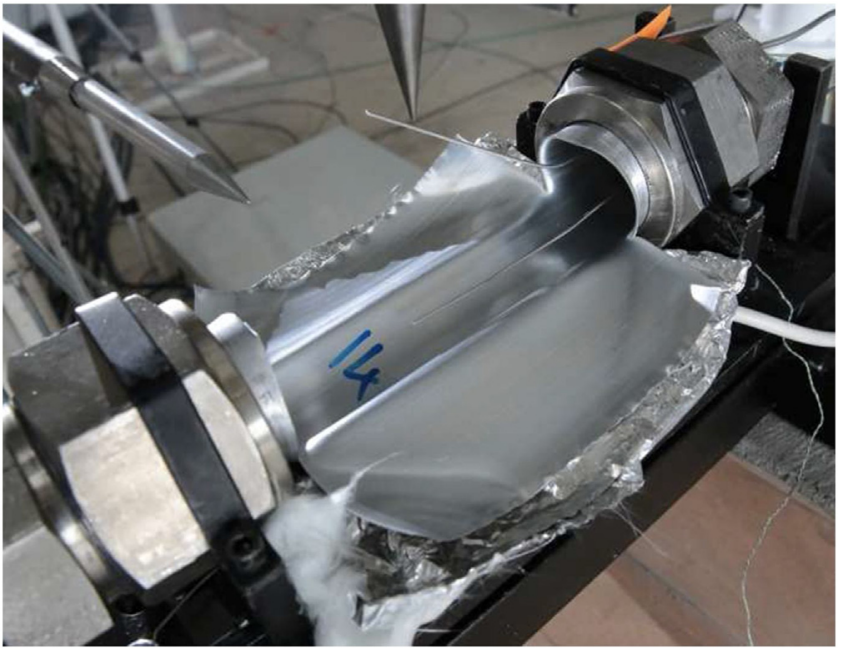

Fig. 3. Image of opened tube with flattened part still attached to ends. Failure runs along top of tube and then turns circumferentially at the ends of the weakened length.

force variables, with a qualitative analysis of the results and case comparison.

\section{Experimental setup and variables}

To study these details, a small scale apparatus was designed to record detailed images of the failure process and to measure overpressures very near to the vessel ( within $R / D_{\text {vessel }}=0.175 / 0.050$ =3.5).

The apparatus involved an aluminum tube with an external diameter $\mathrm{D}=50.8 \mathrm{~mm}$, length $\mathrm{L}=300 \mathrm{~mm}$ and nominal wall thickness of $1.6 \mathrm{~mm}$. The apparatus and failure was designed to be representative of a cylinder failing and suffering a BLEVE at its top and centre. Fig. 3 shows the tube after failure. It is representative of the failure of an industrial size horizontal cylinder BLEVE (see Fig. 1)

The apparatus was designed and constructed to study the early moments of a BLEVE in a weakened horizontal cylinder. The key design objectives were:

i) the failure mode should be similar to what is seen in practice with horizontal cylindrical pressure vessels

ii) allow for variable $L / D$ and weakened length $L_{c} / D$

iii) allow for variable failure pressure $P_{f}$

iv) allow for variable fill level $\mathrm{f}$

v) make the vessel as large as possible but small enough to be economically affordable to do many tests

This apparatus consisted of the following parts:

i) aluminum tube (6061 T6 annealed to T0) with $\mathrm{D}=50.8 \mathrm{~mm}$ and $\mathrm{L}=300 \mathrm{~mm}$ with wall thickness $1.6 \mathrm{~mm}$

ii) top of the tube machined to reduce the wall thickness over length Lc to give desired failure pressure in the range 10-35 bar.

iii) Swagelok end caps. One machined to accept fill and vent lines, two sheathed thermocouples (type $\mathrm{K} 1 \mathrm{~mm}$ diameter), pressure transducers (TC-Direct 716-072) and a high speed piezoelectric pressure transducer (PCB M101A02). The other end cap machined to have a $30 \mathrm{~mm}$ diameter window

iv) electric heater machined to cover bottom $30 \%$ of tube surface

v) cradle to hold tube in position vi) blast plate below tube supported on high speed piezoelectric load cells (PCB M202B)

vii) pencil type blast piezoelectric gauges (PCB 137A23) at various positions

viii) high speed video viewing window end, tube side and top (high speed cameras available: Phantom V711, V2512, VEO710 and Photron SA3)

ix) High speed shadowgraph viewing side and end (same cameras) $\mathrm{x}$ ) electric valves to allow for purging, fill and venting the tube

Fig. 4 shows a schematic of the apparatus. Further details of the apparatus can be found in (Eyssette, 2018).

This work focuses on the load cells capturing the ground force signal. The load cells are screwed and pre-constrained under the base plate on which the tube rests. The sensors are piezoelectric load cells placed in each four corners of the based plate holding the tube in place (Fig. 5). The ground force is studied together with the transient pressure inside the vessel, measured by a piezoelectric transducer mounted on the filling end of the tube. It has to be noted that only the compression force was measured by the load cells; any negative effect measurement is not reliable since the mechanical properties of the screws are unknown.

The sensors characteristics are given Table 1:

\section{Results}

In the scope of this paper, 22 tests led to relevant ground force measurements. The parameters varied though this experiment are the failure pressure $P_{\text {fail }}$ (from 11.7 bar to 32.7 bar), the amount of liquid inside the vessel, or liquid fill level $\Phi_{\text {liq }}$, in volume fraction of liquid (from 0 to $87 \%$ ), and the weakened length through machining at the top of the tube, or cut length $L_{c}$ (from $50 \mathrm{~mm}$ to $150 \mathrm{~mm}$ ). The experimental matrix is given Table 2

From our current knowledge of BLEVE, the ground loading considered in this work was due to the pressure and momentum forces caused by the opening of the top of the vessel and the release of the contents. The release was very rapid and explosive. The release produced shock waves. As the vessel opened at the top the vapour space was ejected with explosively expanding vapour and this was followed by the powerfully flashing liquid and the expanding 2phase mixture.

As the vessel failed a jet of vapour was released as described in (Birk et al., 2020). This jet expanded and went sonic just beyond the edge of the failure opening. The jet continued to expand and go supersonic beyond the opening. This jet pushed on the atmosphere and at some point it pushed strongly enough to produce a shock wave that traveled into the surroundings at supersonic speed. The loss of vapour from the vapour space caused a pressure drop that caused the liquid to begin to flash at the liquid surface. This flashing wave grew downwards into the liquid. This boiling wave emptied the vessel. Previous studies (Baker et al., 1983) suggest the flashing liquid process does not produce shocks waves. However, this does not mean the liquid boiling is harmless in the explosion. It is understood that the dynamic loading resulting from the boiling is very significant to propel vessel fragment. Similarly, we assume that it has a major role in generating a destructive ground force. This hypothesis will be commented under the light of the results in this experiment.

\subsection{Frequency response of the system with regard to load signal measured}

A first validation of the results was made by comparing the signal obtained with the transfer function of the simplified equivalent spring-mass system of the plate mounted on the four load sen- 


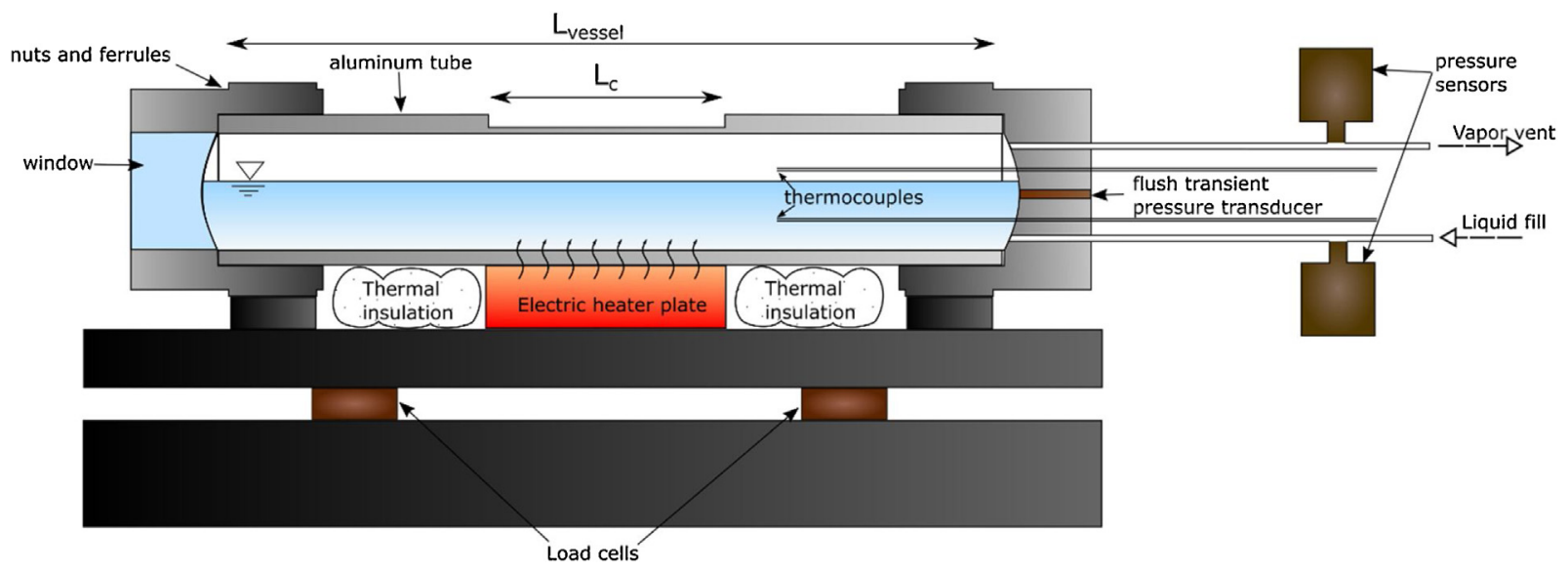

Fig. 4. Schematic diagram of tube apparatus (tube $D=50 \mathrm{~mm}$ ).

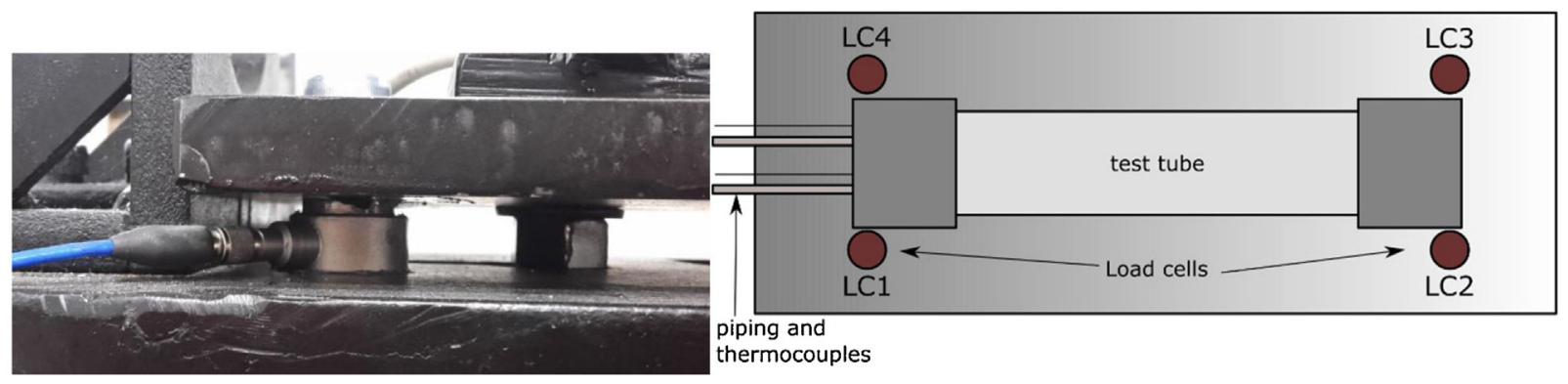

Fig. 5. Load cell mounting under based plate (left) and load cells location around the test tube seen from above (right).

Table 1

Ground load sensor characteristics.

\begin{tabular}{|c|c|c|c|c|}
\hline Sensor use & Designation & Range & Response time & Uncertainty \\
\hline Ground loading & РCВ M202B & $0-44.5 \mathrm{kN}$ & $60 \mathrm{kHz}$ max frequency & $<0.2 \%$ Full scale $(0.01 \mathrm{kN})$ \\
\hline Transient internal pressure & M101A02 & $0-34.5$ bar & $1.5 \mu \mathrm{s}$ & $<0.4 \%$ Full scale (138 mbar) \\
\hline
\end{tabular}

Table 2

Experimental Matrix.

\begin{tabular}{|c|c|c|c|c|c|c|c|}
\hline Test \# & Cut Length (mm) & Pfail (bar) & vol fill (\%) & Test \# & Cut Length (mm) & Pfail (bar) & Fill (\%) \\
\hline 2 & 150 & 11.7 & 52 & 15 & 150 & 15.5 & air \\
\hline 3 & 150 & 13.4 & 55 & 16 & 150 & 16.0 & 5 \\
\hline 4 & 150 & 15.6 & 59 & 18 & 150 & 18.5 & 61 \\
\hline 5 & 150 & 16.7 & 63 & 19 & 150 & 30.6 & 65 \\
\hline 6 & 150 & 17.0 & 59 & 20 & 150 & 26.9 & 63 \\
\hline 7 & 100 & 18.8 & 58 & 21 & 150 & 19.3 & 86 \\
\hline 8 & 100 & 12.5 & 57 & 22 & 150 & 23.3 & 87 \\
\hline 9 & 50 & 19.0 & 55 & 23 & 150 & 32.7 & 70 \\
\hline 10 & 50 & 19.1 & 15 & 24 & 150 & 26.3 & 24 \\
\hline 11 & 150 & 17.7 & 17 & 25 & 150 & 29.5 & 18 \\
\hline 14 & 150 & 18.3 & 18 & 26 & 75 & 18.6 & 57 \\
\hline
\end{tabular}

sors (Fig. 6). The tube is mounted on a plate weighting $M_{\text {plate }}=6.3$ $\mathrm{kg}$. With a stiffness per sensor of $\mathrm{k}_{\text {sensor }}=2.8 \mathrm{kN} / \mu \mathrm{m}$, the natural frequency of the system is $6.7 \mathrm{kHz}$.

$f_{0}=\frac{1}{2 \pi} \sqrt{\frac{4 k_{\text {sensor }}}{M_{\text {plate }}}}=6.7 \mathrm{kH}$

The system behaves like a low-pass filter with this cut-off frequency. This value was compared to the Fourier spectrum of a ground force measurement signal (Fig. 7). All the significant contributions to the ground force act in a frequency range way below the natural frequency of the system ( $<1 \mathrm{kHz}$ for most of it, up to 2 $\mathrm{kHz}$ for smaller contributions).

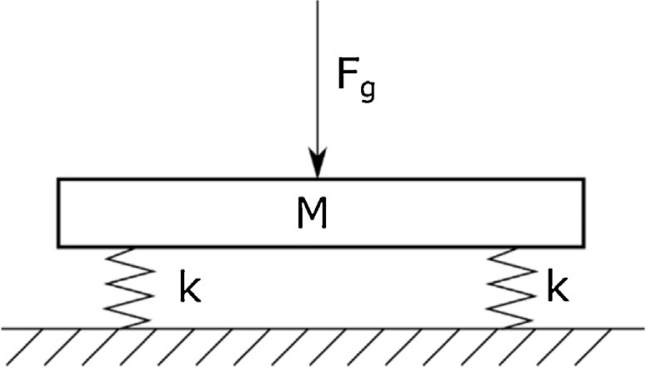

Fig. 6. Equivalent mass spring system. 

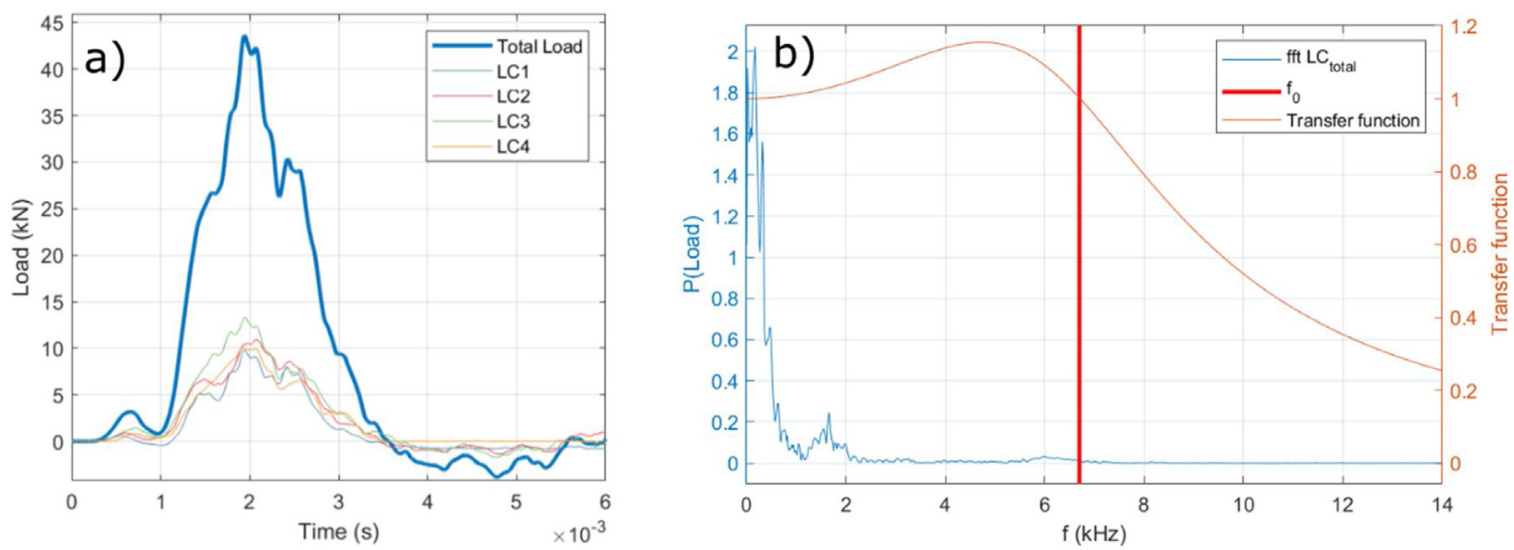

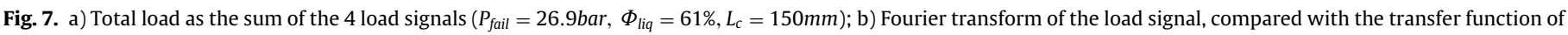
the critically damped equivalent mass-spring system.

\subsection{Air burst and low liquid volume content burst ( $<25 \%)$}

The discussion of the liquid and vapour contribution to the ground loading starts with the study of an air burst with the small scale apparatus, to get a sense of what a vapour ground force may be. The ground force signal of this case is presented together with the internal pressure measured at one end of the vessel (Fig. 8a). The tube after failure is shown Fig. 8 right. Time $t=0$ corresponds to the start of the crack opening of the tube. The pressure starts dropping after $0.5 \mathrm{~ms}$ at the sensor, which corresponds to the time for the expansion to propagate from the tube top center, where the crack opens, to the sensor location $(0.43 \mathrm{~ms})$. Pressure then drops below atmospheric pressure, before increasing again to this stable value $(\mathrm{t}=4 \mathrm{~ms})$. The ground force peak is $9.6 \mathrm{kN}$. It presents a first peak at $3 \mathrm{kN}$, followed by the main peak. Its duration is $3.3 \mathrm{~ms}$. The maximum ground force obtained for this vapour burst at 13 bar is approximately $10 \mathrm{kN}$. It is observed $1 \mathrm{~ms}$ after the internal pressure dropped to its minimum. An interpretation of this delay is done by expressing ground force as $\mathrm{F}=$ Internal pressure $\mathrm{x}$ Horizontally projected area of application of this pressure. Initially, the pressure is high when a small projected area becomes available at tube opening. The force increases consequently. Then, the pressure drops, but the opening area increases fast enough, such that ground force keep increasing up to its maximum. Finally, pressure is back to ambient conditions, surface area stabilizes, force drops. However, the behavior of internal pressure being taken in one point only limits the conclusions on that point.

The tube after rupture shows that the compressed air burst did not flatten the vessel as it is seen commonly for BLEVE, unlike all cases with liquid propane present in the tube. It illustrates one destructive characteristics of the liquid boiling at that scale.

Another interesting case in this study was made with a low liquid volume fill of propane ( $5 \%$ of liquid). The order of magnitude of the maximum peak force is the same $(9.5 \mathrm{kN})$, even though the failure pressure is higher for the second case (Fig. 9a). The internal pressure profile shows a steady drop down to atmospheric pressure. The tube was more flattened than with the air case, which means there was more energy in the vessel to open it up (Fig. 9a). This may be due to the $5 \%$ of liquid boiling. Moreover, a second peak occurs on the ground force signal after the main peak, reaching 6.3 $\mathrm{kN}$. This may illustrate the liquid boiling process, with a smaller peak because of the small quantity of liquid.

Similar behaviour is observed on five other cases in the range of $15-20 \%$ liquid volume fill. The contribution of each phase can be observed on one test with graphical approximations (Fig. 10). In the following figures, the liquid and vapor contribution are used only for illustrative purpose to help understanding the argument. These are graphical approximations, they do not account for a complete and accurate description of the physics of the opening process. The data collected do not allow analyzing the phenomenon into such details yet.

\subsection{Violent boiling profiles}

For a majority of cases with larger filling content, the ground force recorded ended up being two to five times larger than the vapour dominated cases. The clear two peaks noticed in the case of low liquid content is not visible anymore, and is replaced by a single large peak (Fig. 11).

When observing the transient pressure inside the vessel, many cases reveal a pressure rise after the initial pressure drop. This pressure rise is characteristic of the superheat boiling repressurizing the vessel. The transition from pressure drop (expansion of the vapour and superheat of the liquid) to pressure rise (boiling of the superheated liquid) is clear on Fig. 11. This transition happens simultaneously with the start of the main ground force increase. The correlation between the two events leads us to believe that the liquid boiling process contributes strongly to the main ground force.

Another feature noticed with several cases is that the maximum peak of the ground force is synchronized with the time at which the vessel ends up fully flattened. On the images of Fig. 12, we see the vessel from the radial view, at different times, starting right at the opening $(t=0)$ until the tube is fully flattened $(t=2-2.5 \mathrm{~ms})$. This time range corresponds well to the time at which ground load signal reaches its maximum. A physical interpretation of this correlation is the following: the pressurized flow generates a vertical downward force on the tube that becomes maximum when the area exposed to the ground is maximum.

\subsection{Load associated to asymmetric opening}

In some tests, the initial crack didn't lead to a symmetric opening of the vessel. Only one side of the tube was flattened while the opposite remained cylindrical (Figs. 13(b) and 14 (b)). Both tests with $50 \mathrm{~mm}$ cut length presented the asymmetric behavior, and only those tests. Some references state that it is the limit condition to actually generate a BLEVE with a cylindrical vessel (Birk et al., 2007). The consequence on the vertical ground force is an uneven distribution of the load on the different load cells (Figs. 13(a) and 14 (a)) compared to other cases with a more symmetric opening (Fig. 7(a)). More importantly, the main direction of the ground force was not vertical, but tilted toward the center of the opening (30 to $45^{\circ}$ angle from the vertical), while the ground loading sensors were 

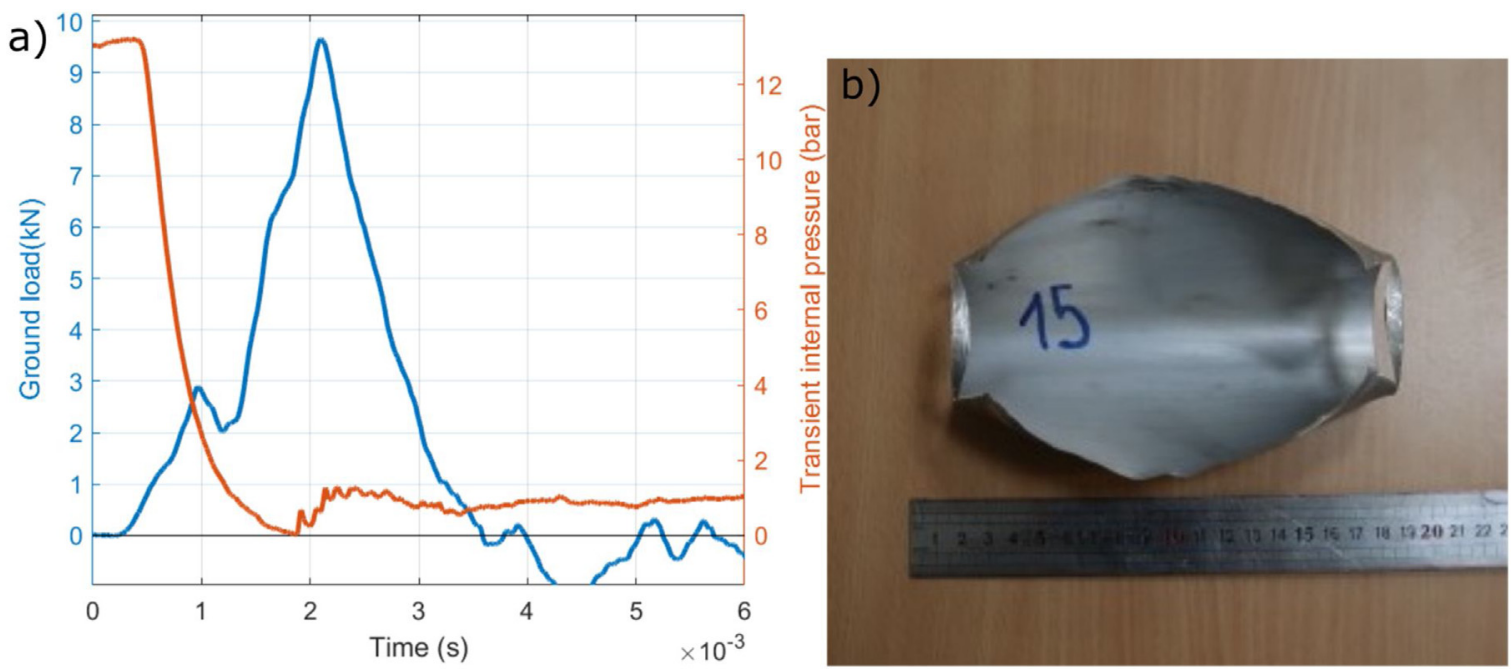

Fig. 8. Air case rupture ( $\left(P_{\text {fail }}=13 \mathrm{bar}, L_{c}=150 \mathrm{~mm}\right.$, filled with compressed air $)$ a) Ground force and internal pressure measurements after failure; b) Shape of the tube after failure.
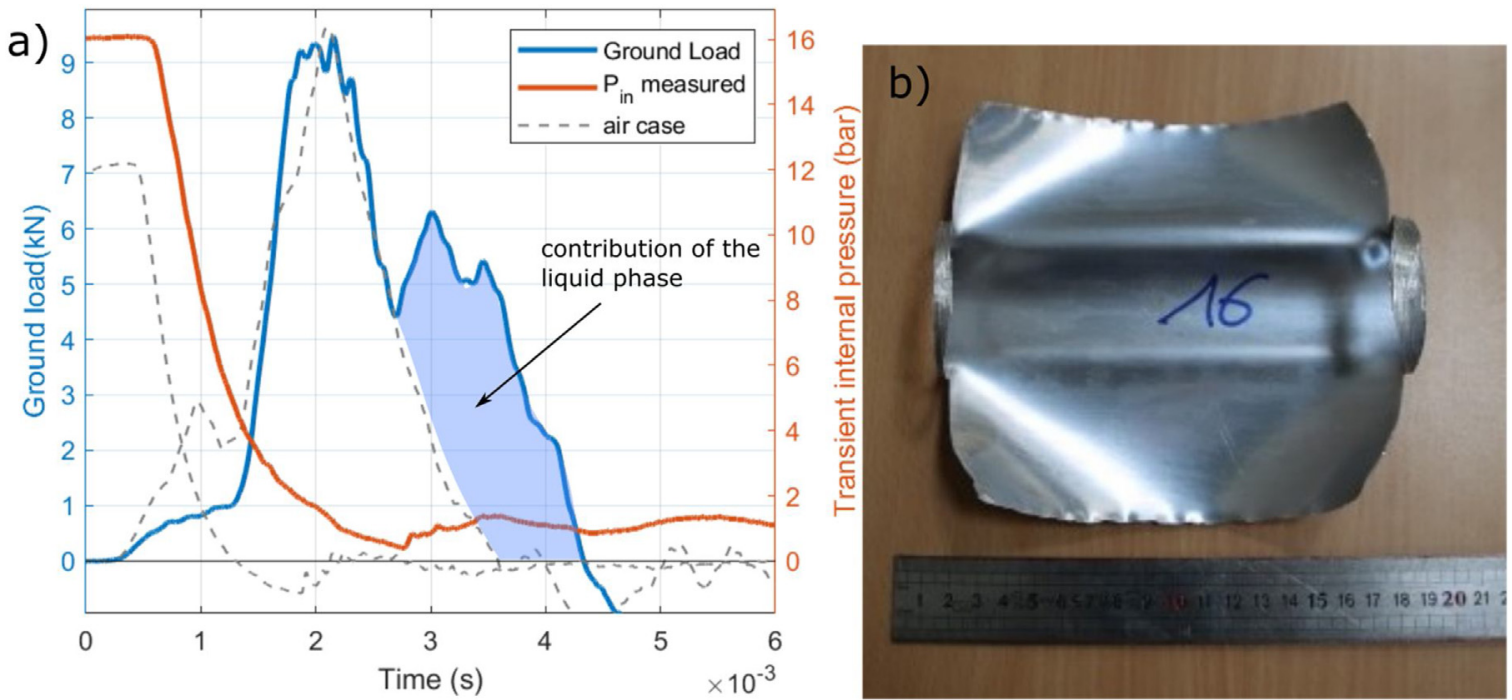

Fig. 9. Propane vapour rupture $\left(P_{\text {fail }}=16 \mathrm{bar}, \Phi_{\text {liq }}=5 \%, L_{c}=150 \mathrm{~mm}\right)$ a) Ground force and internal pressure measurements after failure. Dashed lines show the measurements for the air case, for comparison purpose; b) Shape of the tube after failure.
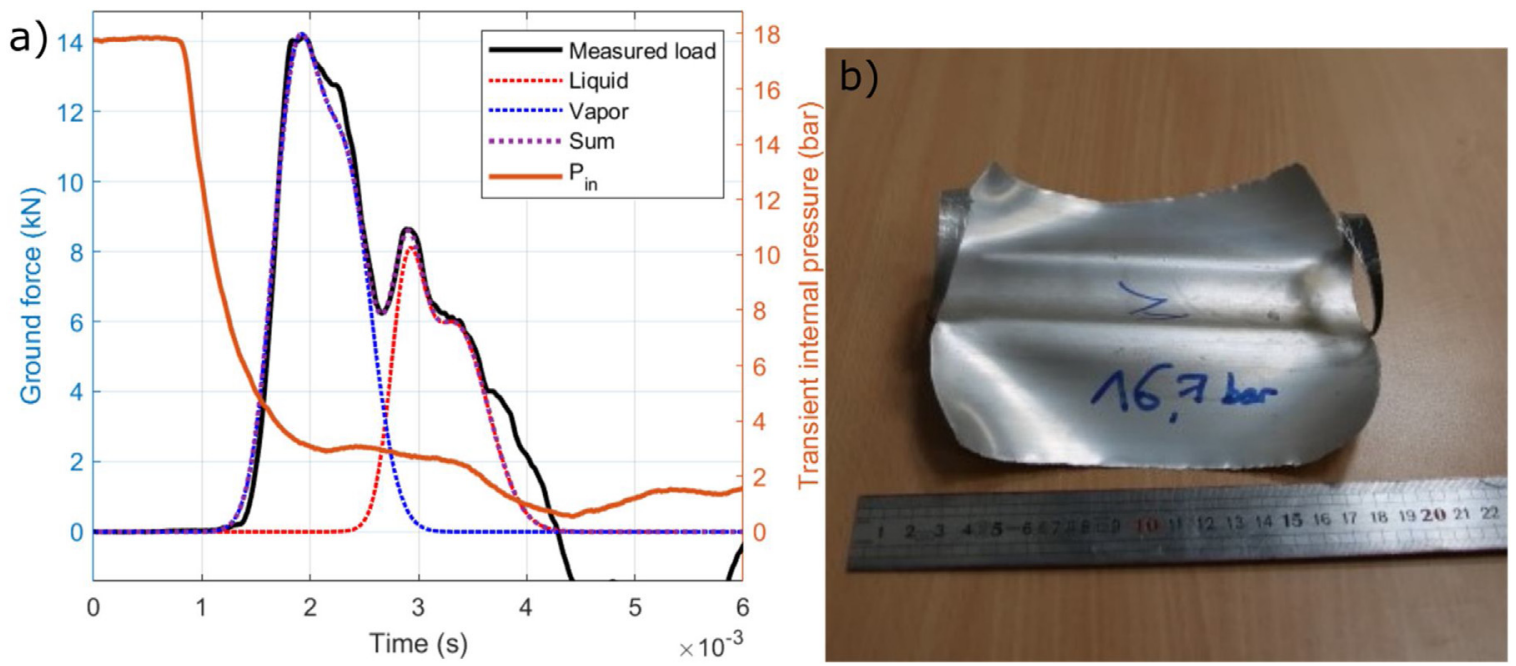

Fig. 10. Internal pressure and ground force from rupture of low liquid content vessel $\left(P_{\text {fail }}=17.7 \mathrm{bar}, \Phi_{\text {liq }}=17 \%, L_{c}=150 \mathrm{~mm}\right)$ a) Ground force and internal pressure measurements after failure; b) Shape of the tube after failure. 

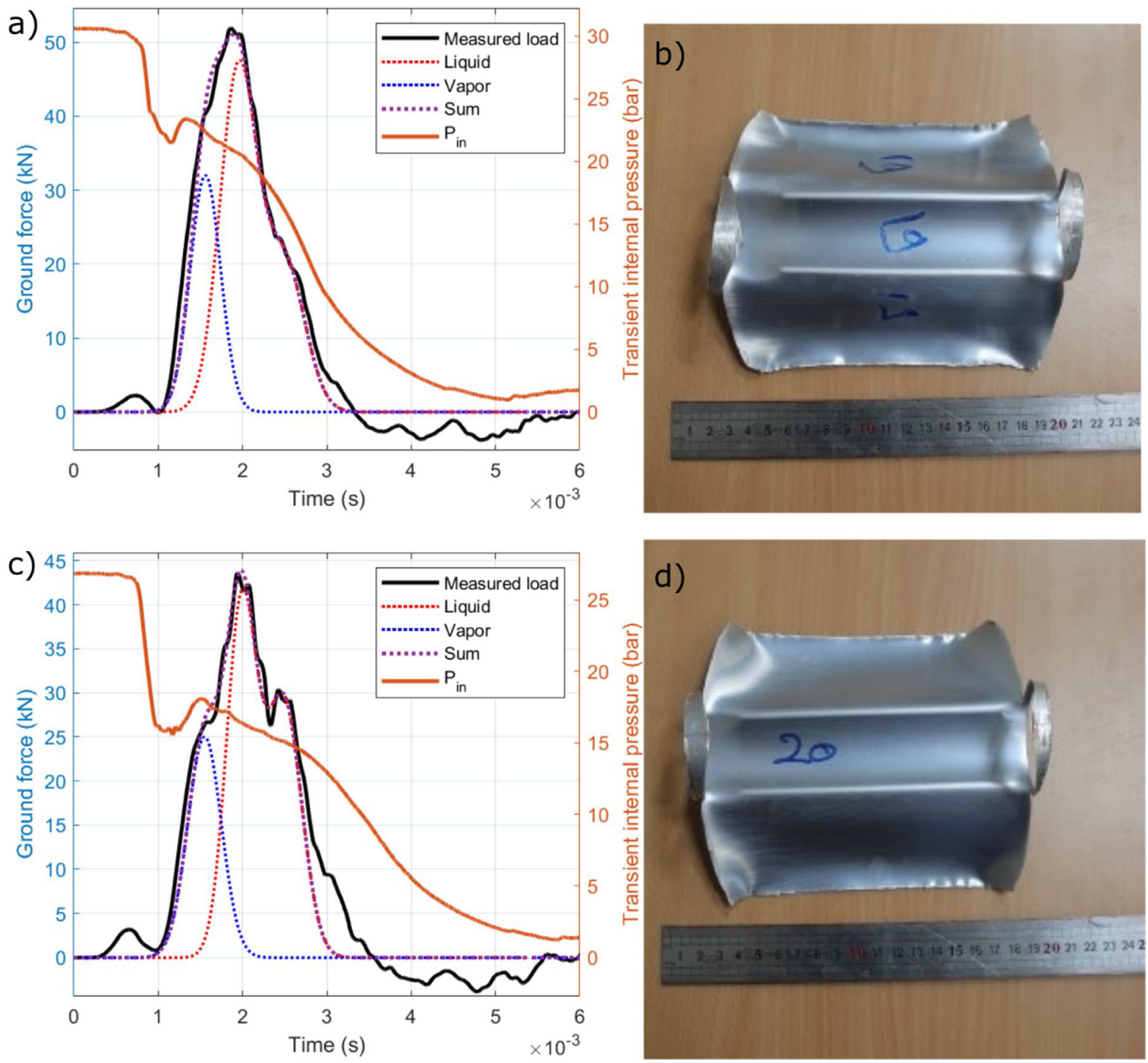

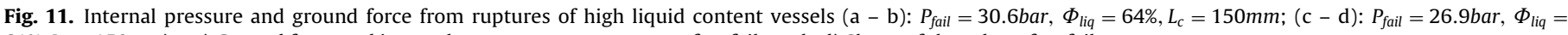
$61 \%, L_{c}=150 \mathrm{~mm}$ ) a-c) Ground force and internal pressure measurements after failure; b-d) Shape of the tubes after failure.

mounted to measure a vertical force only. This means some information is missing on these two cases for the full characterization of the ground force. Two major differences between these two cases are the liquid fill content and the behaviour of the transient pressure in the vessel: it rises after the initial undershoot for the case with more liquid Fig. 13a), and drops continuously for the case with low liquid content (Fig. 14a).

All the experiments show the same fragmentation pattern: crack opening at the top and symmetric flattening. This is the most common opening pattern for a cylindrical vessel engulfed in fire. It might also be considered as the worst case in term of ground force hazard. The only variation of pattern observed through experiments is the asymmetric opening mentioned in the previous paragraph, for two experiments with short cut length.

\subsection{Presence of a small first load}

On some cases, the presence of a small initial load before the main ground force peak was noticed. The cases have been sorted in categories based on the presence or absence of this initial load (Fig. 15). The initial load ranges from $0.7 \mathrm{kN}$ to $3.1 \mathrm{kN}$, while the main peak of the ground force ranges from 10 to $55 \mathrm{kN}$. The small load, when present, is less than $10 \%$ of the maximum ground force peak.

The presence of the initial small load was reported for all relevant tests based on their failure conditions, by plotting the initial conditions of all relevant tests on (fill - Pfail) plane (Fig. 16). For explosions with large cuts $(150 \mathrm{~mm})$ the initial load was generally present with a combination of high failure pressure and high fill level. Explosions with smaller cuts do not obey that rule, as they seem to no trigger the initial in general. Finally, two outliers in the low fill - low failure pressure side are noticed as well: a case mostly vapor (Fig. 9) and a case with $20 \%$ liquid and 18 bar failure.

The focus is made on the latter outlier (Fig. 17). When comparing the time at which this initial load appears and disappear with high speed imaging from the side of the vessel, the load seems to start when the crack, initially propagating longitudinally, reaches the ends of the machined lengths of the tube, to then start propagating circumferentially (Fig. $17 \mathrm{t}=0.4 \mathrm{~ms}$ ). The change of propagation direction in the crack may be the origin of a change in the rate of growth of the opening area. This is an important parameter to consider if the ground force is visualized as the thrust through a nozzle of increasing cross section area. The small load ends during the circumferential opening process. 


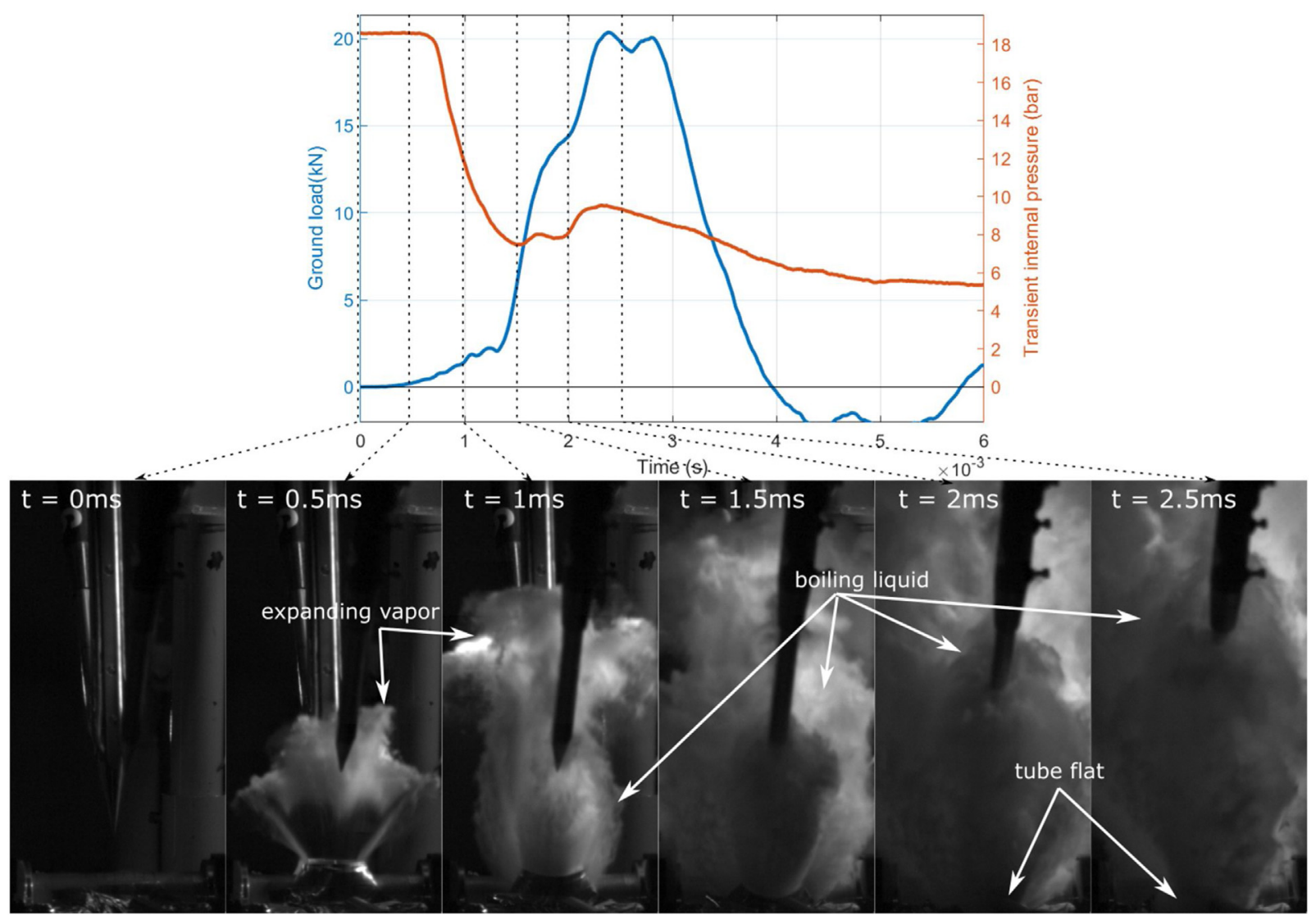

Fig. 12. Comparison of events on the ground load signal with the high speed imaging radial view at various times $\left(P_{\text {fail }}=18.6 \mathrm{bar}, \Phi_{\text {liq }}=57 \%, L_{c}=75 \mathrm{~mm}\right)$.
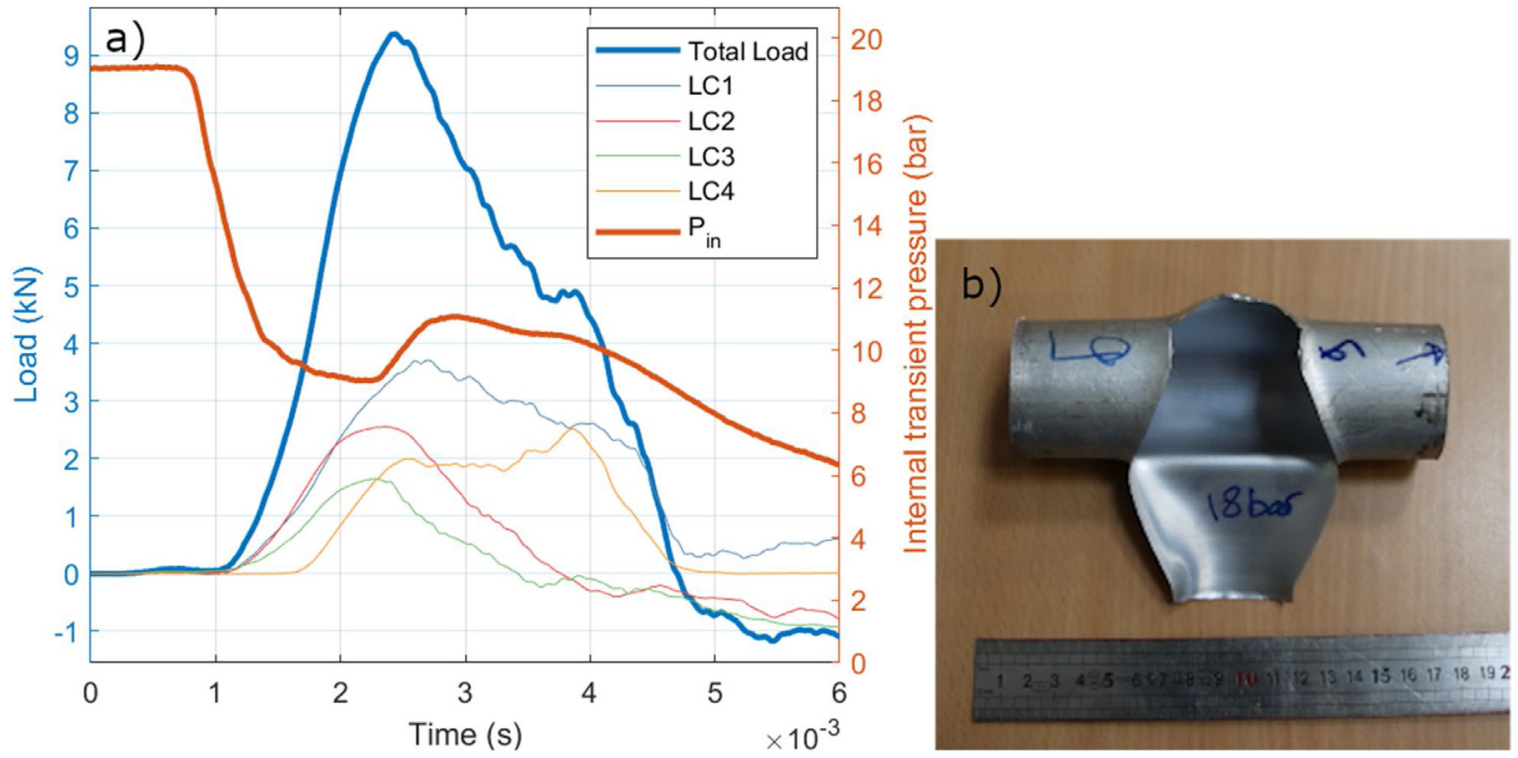

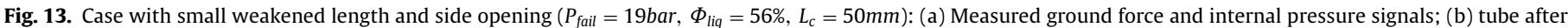
failure.

When comparing the small load with the expansion of the cloud, it is clearly in sync with the initial vapor exit while the main component of the load corresponds to the appearance of the thicker boiling cloud coming after. A correlation can be made between these phenomena: when the vessel starts opening, the compressed vapor goes out of the crack, generating a force through a small opening area. The crack continues to propagate, opening a larger area for the fluid to expand, while the tube progressively gets flattened horizontally. At the same time, the liquid boils and is propelled out of the vessel. This observation leads to conclude that initial ground load would be due to the first instants of vapor expansion, while the main load is from the liquid boiling.

However explaining the initial load this way does not explain the strength of the ground force observed with the air case (Fig. 8) 

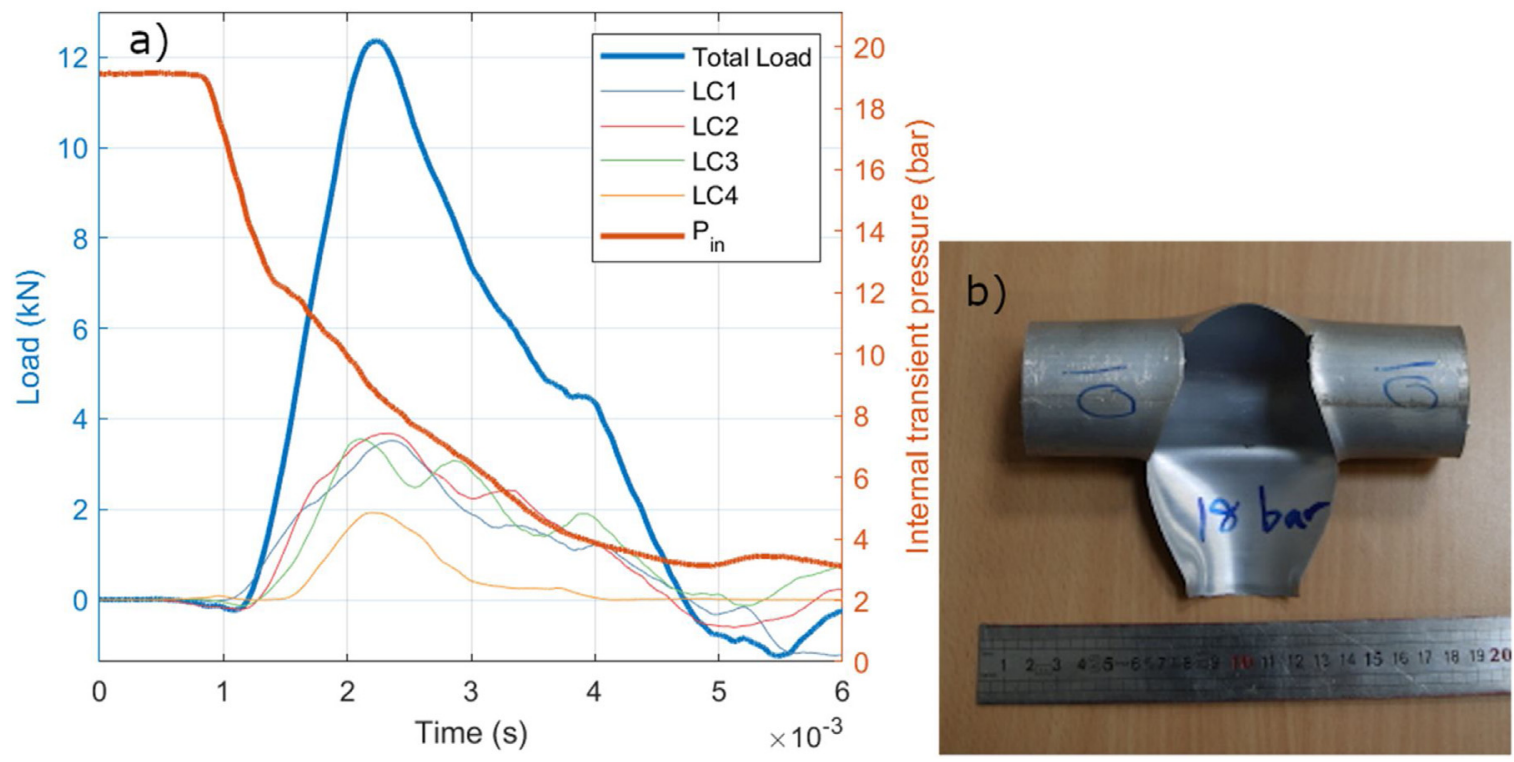

Fig. 14. Case with small weakened length and side opening $\left(P_{\text {fail }}=19.1 \mathrm{bar}, \Phi_{\text {liq }}=16 \%, L_{c}=50 \mathrm{~mm}\right)$ : (a) Measured ground force and internal pressure signals; (b) tube after failure.
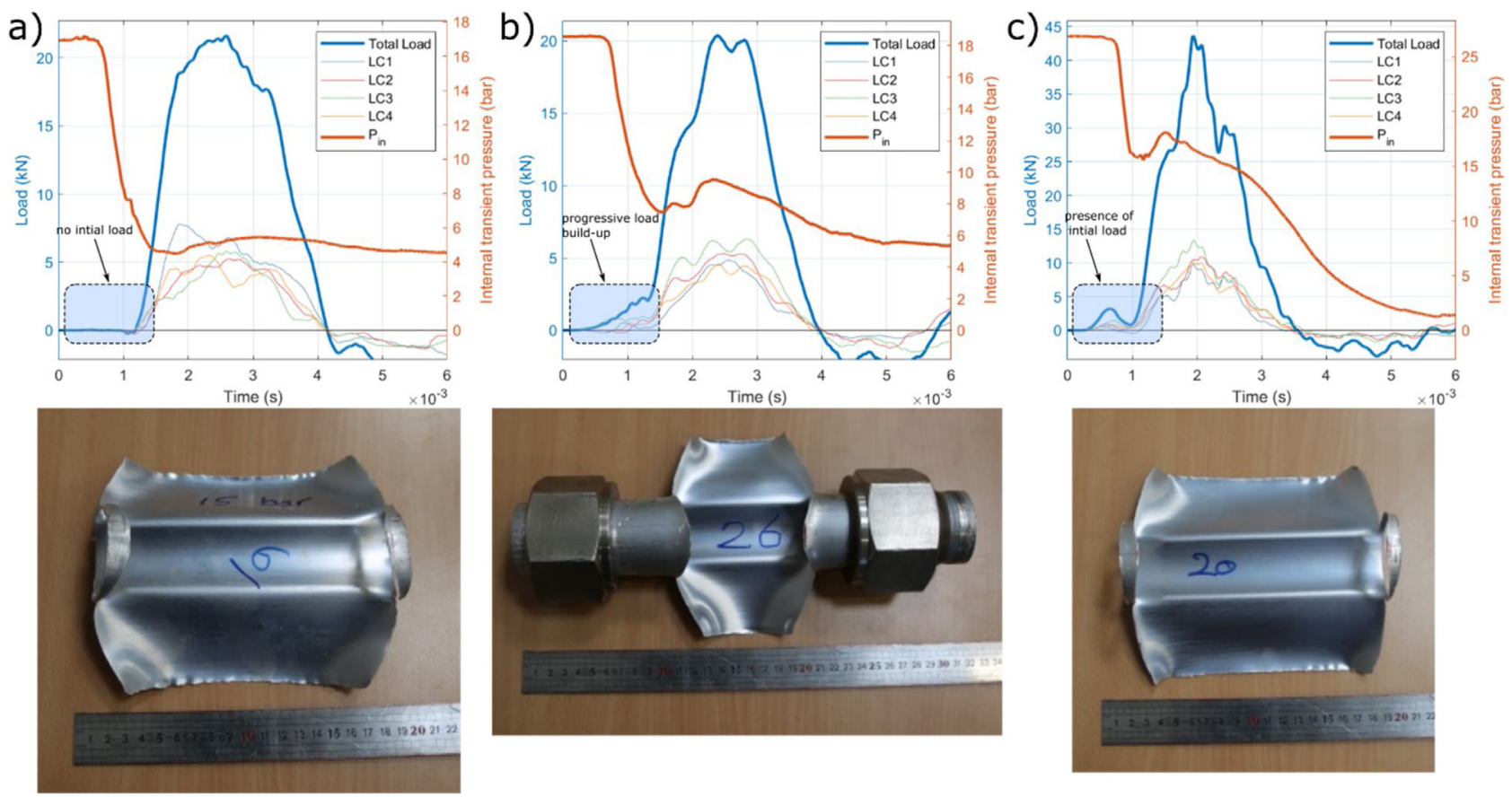

Fig. 15. Ground loading measurement, gage by gage and total sum for 3 different profiles:

a) No small load: $P_{\text {fail }}=17 \mathrm{bar}, \Phi_{\text {liq }}=60 \%, L_{c}=150 \mathrm{~mm}$.

b) Progressive load build up: $P_{\text {fail }}=18.6 \mathrm{bar}, \Phi_{\text {liq }}=56 \%, L_{c}=75 \mathrm{~mm}$.

c) Presence of a first small load: $P_{\text {fail }}=26.9 \mathrm{bar}, \Phi_{\text {liq }}=61 \%, L_{c}=150 \mathrm{~mm}$.

and goes against the argument made for the vapor case (Fig. 9). The comprehension of the presence or absence of this initial load remains unclear to some extent, requiring extra tests to confirm or infirm these hypotheses.

\section{Parametric analysis of maximum ground force and impulse}

From the signals observed before, three main characteristics were extracted: maximum ground force, positive impulse of the main force contribution, and duration of this positive impulse. They are plotted against the experimental variables (failure pressure, liq- uid fill level, cut length), to gage the influence of each parameter on the measurements, to present a preliminary dimensional analysis.

\subsection{Influence of failure pressure on load variables}

The behavior of maximum force, impulse and duration of impulse is plotted in Fig. 18. To observe relatable results, the focus was made on tests with similar fill levels, between 50 and $70 \%$. The general trends observed are the following:

- Maximum ground force increases linearly with failure pressure when observing the results with similar cut length $(150 \mathrm{~mm})$. A 


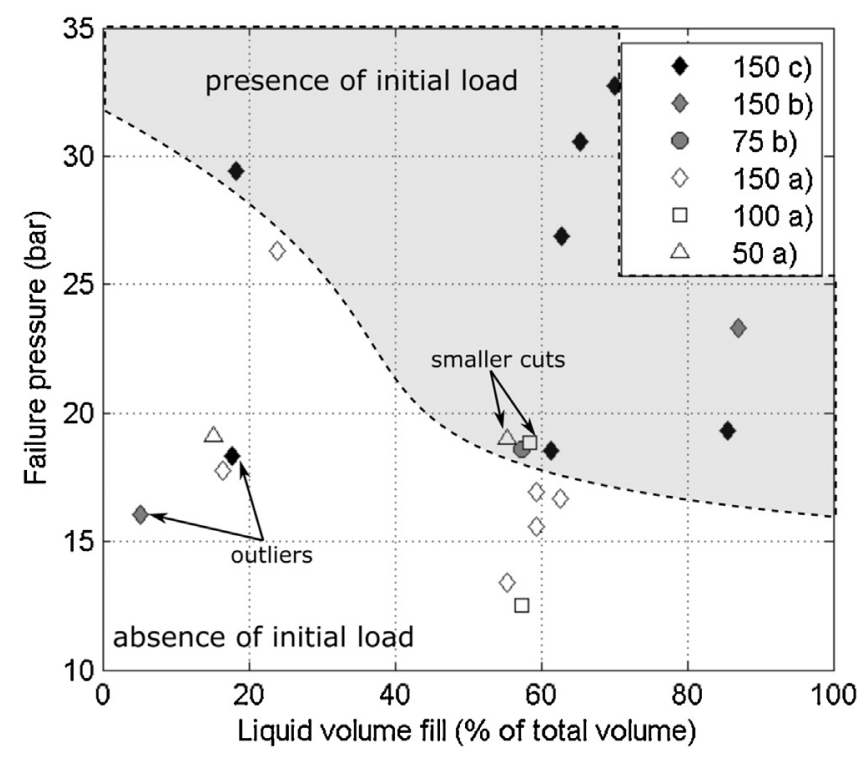

Fig. 16. Test summary with specification of the presence or not of initial load, symbols differentiate cut lengths (a) No initial load; b) Initial load merged with main load; c) clear separated initial load).

few low pressure cases (14-19 bar) show similar maximum force. This can be interpreted as follow: for strong failure pressure $(>20$ bar), force can be seen as a pressure applied to a constant surface area. Thus, the stronger the pressure, the stronger the force. The change of behavior below 20 bar is unexplained yet. It may be related to superheat limit temperature (around $53^{\circ} \mathrm{C}$ for propane, near 18 bar).

- Duration of impulse decreases linearly with failure pressure for similar cut length $(150 \mathrm{~mm})$. The higher the pressure, the higher the temperature and the more violent the boiling will be, leading to a faster emptying of the vessel.

- Impulse increases also linearly with failure pressure for $150 \mathrm{~mm}$ cut cases. A few low pressure cases (14-19 bar) deviate from this general trend, with impulse varying against failure pressure. Impulse being the integral of force over time, the stationary behavior of maximum force at low failure pressure combined with constant linear relation between time and failure pressure lead to this change in behavior.

\subsection{Influence of liquid fill level on load variables}

The behavior of maximum force, impulse and duration of impulse is plotted in Fig. 19. To observe relatable results, the focus was made on tests with similar rupture pressure, between 17 and 19 bar. The general trends observed are the following:

- Maximum ground force increases with liquid fill level. More liquid means more matter expanding to build up the pressure that is applied to the vessel wall during and after the flattening process.

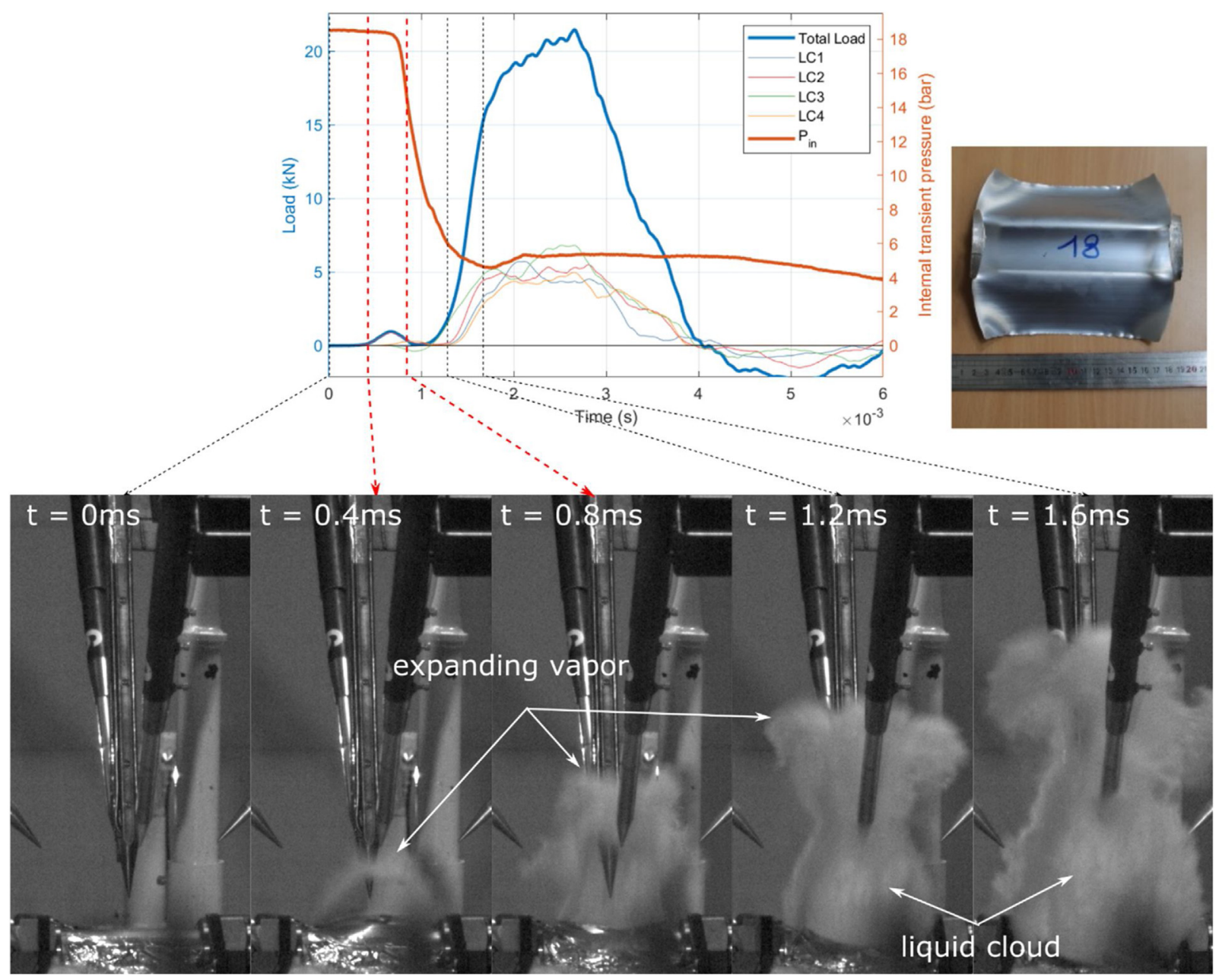

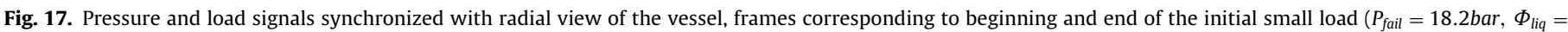
$20 \%, L_{c}=150 \mathrm{~mm}$. 

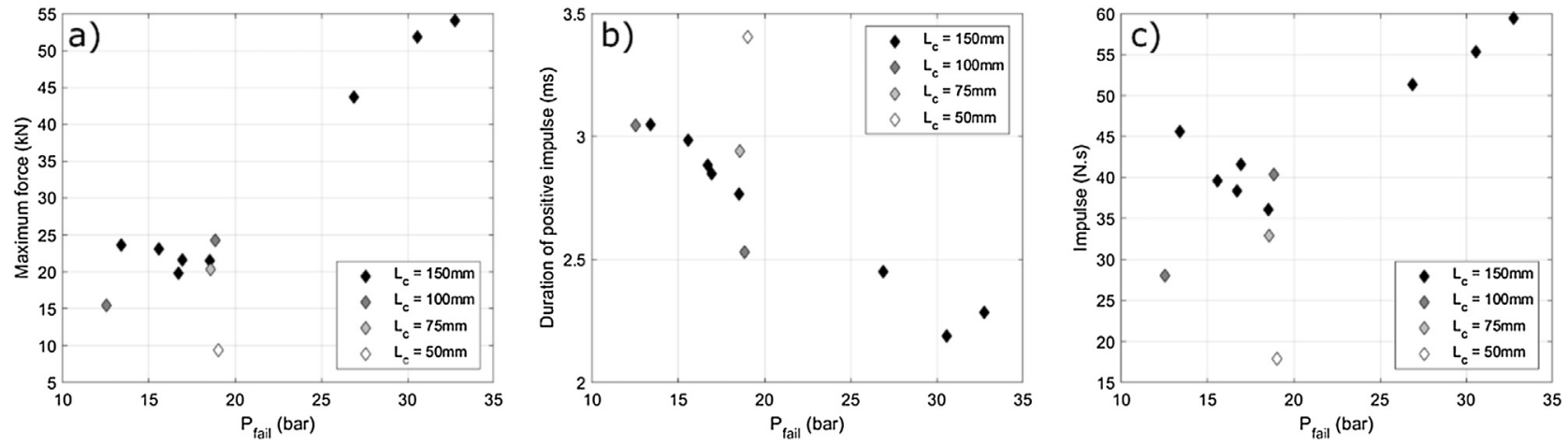

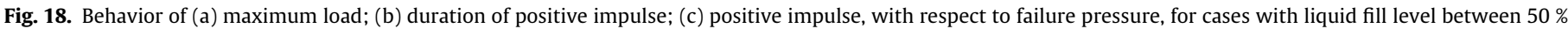
and $70 \%$.
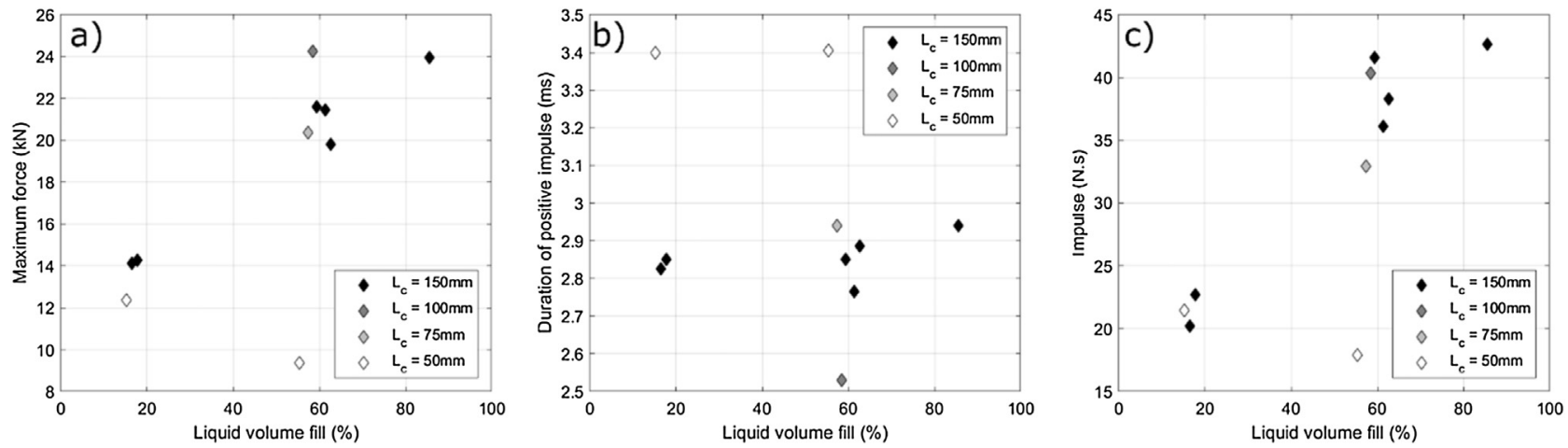

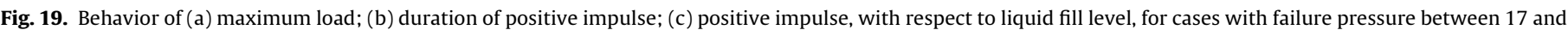
19 bar.
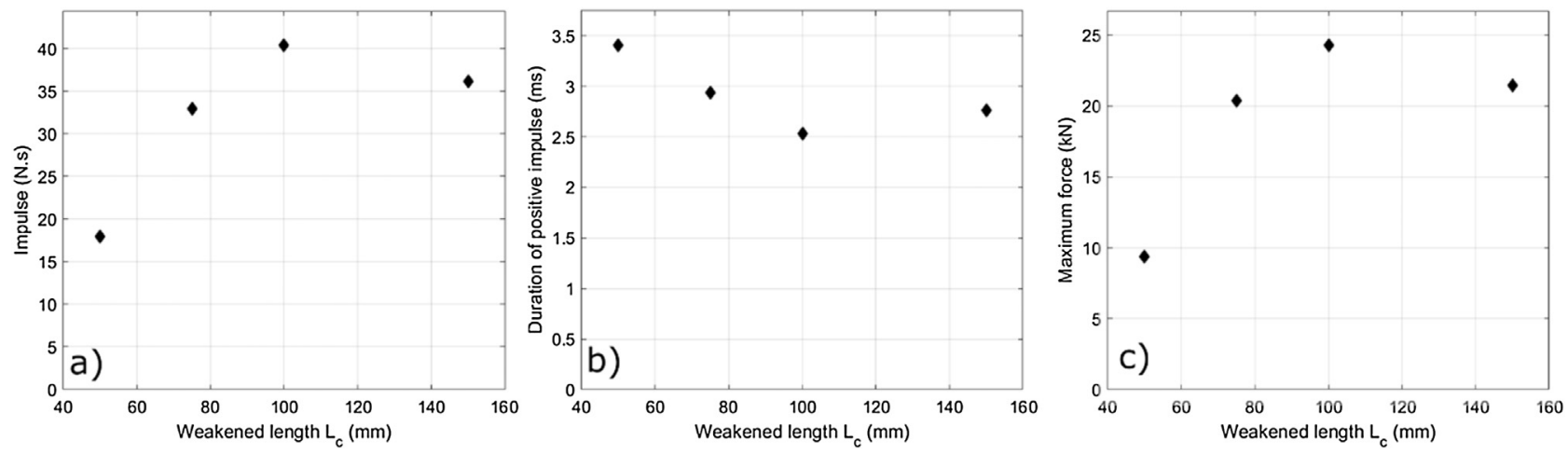

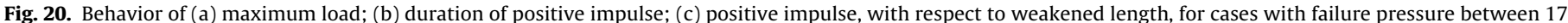
and 19 bar.

- Duration of positive impulse is constant or slowly increasing with increasing liquid fill level. This is counterintuitive at first, as once would expect that more liquid takes longer to be evacuated from the vessel for similar opening. There is no explanation to this behavior yet.

- Impulse, as expected is a combination of the two previous behaviors. Thus it increases with liquid fill level, as the maximum ground force gets stronger.

\subsection{Influence of weakened length on load variables}

Four cases were compared because they have similar failure pressure (around 19 bar) and fill level (around $60 \%$ ), but different cut lengths. The behavior of the force measurements with respect to the weakened length is plotted in Fig. 20. Maximum force and impulse increase together with weakened length, while duration of positive impulse decreases. An explanation for this could be that larger the weakened length, the larger the surface area on which the boiling liquid can exert its pressure, increasing the maximum force. On the other hand, the larger the area of release, the quicker the vessel empties, decreasing the duration of positive impulse. The impulse being a combination of force and duration, its behavior is dictated by the dominant behavior of these two: seemingly maximum force. It should also be remembered when observing the results for the case with $50 \mathrm{~mm}$ cut length that the opening was asymmetric. The fragmentation pattern may be a contributing factor to the low ground force.

Finally, a limit to this trend appears between $L_{c}=100 \mathrm{~mm}$ and $150 \mathrm{~mm}$, where all these variables fall of the trends mentioned above. An attempt to explain this behavior could be the following: 
at a given pressure and fill level, for the force to be maximum, the opening should be large enough so that the surface of application of the pressure on the ground is large, but small enough to keep a large pressure inside the vessel for a longer duration due to the repressurization mechanism. However, having only four measurement points is not enough to validate this hypothesis yet. More data needs to be collected from experiments.

\section{Conclusion}

This work presented the experimental measurements of the ground force generated by a small scale BLEVE (0.6 L vessel). The maximum ground force ranged from $10 \mathrm{kN}$ to $54 \mathrm{kN}$, and the impulse from 16 to 60 N.s. The shape of the signals synched with the transient pressure in the vessel showed the potential contribution of the vapour expansion through a partial opening and the liquid boiling on the fully opened vessel.

The contribution of liquid and vapor phase is not clear yet. No general behavior could be identified within this set of data. When looking at a case with air only or mostly propane vapor, the ground force generated is similar to some cases with more liquid. However the strongest loads are observed with large liquid fill content and strong failure pressure. Small initial loads observed in some cases coincide with vapor expansion, confirming that liquid boiling may be the main contribution of the ground.

Finally the interpretation of the behaviors of load variables (maximum ground force, duration of impulse and impulse) with the experimental parameters (failure pressure, liquid fill level and weakened length) show that failure maximum ground force are positively and linearly correlated to failure pressure and liquid fill level.

Simple modeling methods needs to be implemented with dimensional analysis in order to make these results useful to industrial size vessels. Then larger scale experiments are required to provide extra data for modeling, as well as validating the behaviors observed with small scale experiments. The ground force is expected to scale up with the dimensions of the vessel mostly. Thermal stratification was not observed in small scale. It is not expected to change the behavior of liquid contribution, and if it does, it should probably reduce it just slightly. But these statements require validation. The end purpose of this work is to predict the ground force generated by the BLEVE of road tankers similar to the case of Bologna 2018, in order to find technical solutions to prevent the damages from it, or implement the proper regulations concerning this hazard in the transportation and storage of pressure vessels.

\section{Declaration of Competing Interest}

The authors declare that they have no known competing financial interests or personal relationships that could have appeared to influence the work reported in this paper.

\section{Acknowledgments}

This work was a collaboration between the Mechanical and Material Engineering of Queen's University in Canada and the LGEI at IMT Mines Alès in France. It was possible thanks to the funding from the Natural Science and Engineering Research Council of Canada with a discovery grant, and the help of the technical team in labs of the Institute of Risk Sciences at IMT Mines Alès, namely Pierre Lauret, Laurent Aprin, Christian Lopez and Pierre Slangen. Dr Stephane Corn and Arnaud Regazzi are also acknowledged for their help in the frequency analysis of the experimental apparatus.

\section{References}

Abbasi, T., Abbasi, S.A., 2007. The boiling liquid expanding vapour explosion (BLEVE): mechanism, consequence assessment, management. J. Hazard. Mater. 141, 489-519, http://dx.doi.org/10.1016/j.jhazmat.2006.09.056.

Baker, W.E., Cox, P.A., Westine, P.S., Kulesz, J.J., Strehlow, R.A., 1983. Explosion Hazards and Evaluation. Elsevier Scientific Pub. Co., http://dx.doi.org/10.1016/00102180(85)90099-9.

Barbone, R., 1994. Explosive Boiling of a Depressurized Volatile Liquid. McGill University, Montreal, Quebec, Canada.

Baum, M.R., 1995. Rupture of a gas-pressurized cylindrical vessel: the velocity of a detached end-cap. J. Loss Prev. Process Ind. 8, 149-161, http://dx.doi.org/10. 1016/0950-4230(95)00017-U.

Baum, M.R., 1998. Rocket missiles generated by failure of a high pressure liquid storage vessel. J. Loss Prev. Process Ind. 11, 11-24.

Baum, M.R., Parry, A.A., 1992. The thrust exerted on a gas-pressurized vessel during axial rupture. Proc. Inst. Mech. Eng. Part C J. Mech. Eng. Sci. 206, 15-24.

Birk, A.M., Davison, C., Cunningham, M., 2007. Blast overpressures from medium scale BLEVE tests. J. Loss Prev. Process Ind. 20, 194-206, http://dx.doi.org/10. 1016/j.jlp.2007.03.001.

Birk, A.M., Heymes, F., Eyssette, R., Lauret, P., Aprin, L., Slangen, P., 2018. Near-field BLEVE overpressure effects: the shock start model. Process Saf. Environ. Prot., 116, http://dx.doi.org/10.1016/j.psep.2018.04.003.

Birk, A.M., Eyssette, R., Heymes, F., 2020. Analysis of BLEVE overpressure using spherical shock theory. Process Saf. Environ. Prot. 134, 108-120, http://dx.doi.org/10. 1016/J.PSEP.2019.11.023.

Eyssette, R., 2018. Characterization and Modeling of Near-field BLEVE Overpressure and Ground Loading Hazards. Queen's University (Canada), IMT Mines Ales (France).

Foglar, M., Hajek, R., Fladr, J., Pachman, J., Stoller, J., 2017. Full-scale experimental testing of the blast resistance of HPFRC and UHPFRC bridge decks. Constr. Build. Mater. 145, 588-601, http://dx.doi.org/10.1016/j.conbuildmat.2017.04.054.

Hashemi, S.K., Bradford, M.A., Valipour, H.R., 2016. Dynamic response of cable-stayed bridge under blast load. Eng. Struct. 127, 719-736, http://dx.doi.org/10.1016/j. engstruct.2016.08.038.

Pietersen, C.M., 1988. The LPG disaster in Mexico. J. Hazard. Mater., 85-107.

Vigilfuoco.tv, [WWW Document] 2018. BOLOGNA (BO) Loc. Borgo Panigale - Esplosione autocisterna. http://www.vigilfuoco.tv/emilia-romagna/bologna/ bologna/esplosione-autocisterna.

Wang, W., Zhang, D., Lu, F., Wang, Schuan, Tang, F., 2013. Experimental study and numerical simulation of the damage mode of a square reinforced concrete slab under close-in explosion. Eng. Fail. Anal. 27, 41-51, http://dx.doi.org/10.1016/j. engfailanal.2012.07.010.

Wang, W., Liu, R., Wu, B., 2014. Analysis of a bridge collapsed by an accidental blast loads. Eng. Fail. Anal. 36, 353-361, http://dx.doi.org/10.1016/j.engfailanal.2013. 10.022 .

Winget, D.G., Marchand, K.A., Williamson, E.B., 2005. Analysis and design of critical bridges subjected to blast loads. J. Struct. Eng. 131, 1243-1255, http://dx.doi. org/10.1061/(ASCE)0733-9445(2005)131:8(1243). 